\title{
Policy Analysis and Policy Analytics
}

\author{
Katherine A. Daniell ${ }^{1}$, Alec Morton ${ }^{2}$, David Ríos Insua ${ }^{3}$ \\ ${ }^{1}$ Australian National University, katherine.daniell@anu.edu.au \\ ${ }^{2}$ University of Strathclyde, alec.morton@ strath.ac.uk \\ ${ }^{3}$ ICMAT, CSIC, david.rios@icmat.es
}

\begin{abstract}
Working from a description of what policy analysis entails, we review the emergence of the recent field of analytics and how it may impact public policy making. In particular, we seek to expose current applications of, and future possibilities for, new analytic methods that can be used to support public policy problem-solving and decision processes, which we term policy analytics. We then review key contributions to this special volume, which seek to support policy making or delivery in the areas of energy planning, urban transportation planning, medical emergency planning, healthcare, social services, national security, defence, government finance allocation, understanding public opinion, and fire and police services. An identified challenge, which is specific to policy analytics, is to recognize that public sector applications must balance the need for robust and convincing analysis with the need for satisfying legitimate public expectations about transparency and opportunities for participation. This opens up a range of forms of analysis relevant to public policy distinct from those most common in business, including those that can support democratization and mediation of value conflicts within policy processes. We conclude by identifying some potential research and development issues for the emerging field of policy analytics.
\end{abstract}

KEYWORDS: public policy, policy analysis, analytics, Big Data, decision support.

\section{Introduction}

This special volume aims at exposing the reader to applications of new analytic methods that can be used to support public policy problem-solving and decision processes, which we shall call policy analytics.

The last few decades have seen rapid growth in the capacity of businesses to exploit information technology (IT), Operations Research (OR), and statistical modelling to collect and process operational and market data to support their decision-making processes. As a result, business analytics has become a flourishing field for consulting and business education. In contrast, while government decisions are often supported by traditional forms of policy analysis, including methods such as cost-benefit analysis, few government departments and agencies have yet managed to make the systematic use of data, evidence, OR methods and cutting-edge statistical and machine learning modelling techniques to inform their work. This provides an interesting novelty, from a historical perspective, since quantitative decision support methods have been frequently pioneered in the public sector. For example, social statistics, going back to Quetelet, 
were started in the $19^{\text {th }}$ century to support governments and were based on the idea that statistical regularities are signals of deeper realities (Gigerenzer et al. 1989; Stigler 1990; Pollock and Maltz 1994). Similarly, the Operations Research field was born during World War II in the service of the UK and US military and grew rapidly based on the development of various methods for supporting defence decision-making (Blackett and Blackett 1962).

Compared with their counterparts in the private sector, public sector decision-makers face several challenges. In particular, public sector problems typically involve making decisions for society at large. Indeed, policy makers in the public sector confront difficulties in deciding how public resources are to be allocated, since the whole underlying purpose of public policy and associated politics is about "deciding who gets what, when and how" (Lasswell 1936). Since such resources are scarce, choices need to be made, as in the famous Guns versus Butter disjunctive. Moreover, if we focus on democratic systems, the features that characterize public sector decision-making include that:

- The public and/or its representatives make decisions, depending on how much participation is introduced;

- Public servants will usually manage the organization within which the decision is to be made;

- The general public actually pays for the analysis through their taxes;

- The general public actually bears the major impacts of the decision, typically without the opportunity of withdrawing their participation;

- The ultimate measure of the outcome of a decision or a policy is typically nonmonetary; and

- The methods used to inform decisions may be subject to public scrutiny.

Other issues that differentiate decisions in public versus private sectors include that political concerns and effects of multiple cultures and co-existing value systems can be more extreme and, in particular, may be affected by the short time (electoral) horizons of representatives, with the ensuing risk of shortsightedness. There may be also organizational structures that are more bureaucratic and difficult to navigate because of their inherent inertia.

Against the backdrop of these basic features of public sector decision-making, we will start by briefly reviewing key ideas from the literature on policy analysis as it forms the conceptual and practical point of origin where analytical methods linked to policy decision-support are most commonly evoked and employed. We then make reference to analytics and business analytics, so as to sketch out what can be specifically classified as policy analytics, before introducing the papers in this volume. We conclude by sketching several relevant research directions in this emerging field. 


\section{Policy Analysis}

Policy analysis refers to a multi-faceted field of activities and roles that has been outlined in various ways in the literature. Here we provide only a brief review of some of the most important concepts. For additional ideas, readers are referred to Pollock and Maltz (1994), Stokey and Zeckhauser (1978), Quade (1975), Mayer et al. (2004), and Fischer et al. (2007).

Firstly, policy analysis may be viewed as a framework for thinking about policy problems and making choices, which could comprise typical stages in decision support (e.g., French et al. 2009; Clemen and Reilly 2014), such as: establishing the problem context; determining the alternative policy options; predicting their consequences; valuing their outcomes; and recommending a policy choice. It is often viewed as part of an ideal 'policy making cycle', which is usually seen as a continuous process cycling through the following general steps, which can be divided or expanded into more or fewer stages (Lasswell 1956; Dunn 1994; Althaus et al. 2007; Jann and Wegrich 2007):

1. Agenda setting: establishing priorities among the issues of public concern that require policy action or change of previous policies.

2. Analysis: aimed at better understanding a public issue on the agenda. The problem is formulated and alternative policy options are developed and evaluated in order to manage the issue. Evidence is gathered to clarify the 'facts', and interests and objectives of citizens and stakeholders.

3. Policy decision: based on the analysis, a final decision is made and the chosen policy is fully specified.

4. Policy implementation: once a policy is selected, it needs to be put into practice. At this stage, the necessary public resources and regulations are mobilized to make the policy operational.

5. Monitoring: aimed at evaluating, on an ongoing basis, whether the implemented policy is producing the expected results, to identify whether the policy should be changed or new issues need to be considered in the agenda.

Despite having widespread appeal due to its clarity and rational progression, the policy cycle - and rational decision-making processes more generally - are often criticized as rarely reflecting what happens in reality (e.g., Barnard and Simon 1947; Jann and Wegrich 2007), leading to a variety of other ways of conceptualizing the policy process (e.g., Lindblom and Woodhouse 1968; Cohen et al. 1972; Kingdon 1984; Sabatier and Jenkins-Smith 1993; Forester 1993). However, the stages noted above still prove useful in practice to orientate needs and thinking around different forms of policy analysis and the methods used to carry them out (Jann and Wegrich 2007; Daniell 2014).

Within the policy process, in whichever way it is defined, critical issues in public decision-making are determining the criteria used for evaluating policies and determining who is able to influence such choice. Such criteria typically reflect political values and priorities of the government in office, underlying a particular conception of 
'public value'. For example, policies may be evaluated relative to their impacts on social well-being, the environment and economic development. The welfare component may be viewed as the aggregation of individuals' welfare, perhaps making necessary tradeoffs between individuals when Pareto gains are impossible. Tradeoffs may also have to be made with other environmental and economic objectives, leading to conflicts between different actors. Policy analysts may aim at smoothing over such conflicts by seeking policy options that lead to equitable, effective and efficient distribution of goods, services, costs and benefits among members of the society, whatever the political conception of what 'equitable', 'effective', 'efficient' and 'members of society' entails.

Moreover, within a liberal model of democracy, a significant part of the government role is to deal with market failures and become 'the risk manager of last resort' (Matthews 2009). In such a role, there is typically a number of policy options that can be chosen from, including: doing nothing; implementing measures that attempt to improve the working of a market, possibly regulating it by implementing measures that require firms and individuals to behave in specified ways; introducing incentives that influence decisions of individuals and firms; or providing goods and services, through the collective provision of public goods and/or income distribution and/or income redistribution. Policy makers should be aware, however, that governments can fail to delivery their intended outcomes, just as markets may fail to deliver economically optimal ones (Wolf 1993).

Aviation security provides a relevant example in relation to security in interconnected systems. Without external regulation or incentive systems, a standard prisoner's dilemma argument shows that agents tend to avoid investing in security (see Kunreuther and Heal 2003), leading to globally insecure systems. An example showing the tragic consequences of such underinvestment is the 1988 Lockerbie disaster in which terrorists took advantage of an airport security hole in order to plant a bomb on an aircraft. In this case, the International Civil Aviation Organization requires signatory countries to implement a so-called State Safety Program. In turn, based on such programs, states require the intervening agents in the aviation business to implement their own safety programs.

More broadly, the objectives underlying policy analysis activities throughout the policy cycle and associated roles that analysts play in such policy processes vary considerably. For example, recent research concludes that not all policy analysts seek to objectively and pragmatically design and recommend 'best policy options' based on evaluations like those previously described, but rather can take on alternative roles of mediating social conflict, clarifying values and arguments or attempting to democratize policymaking processes. A framework bringing together these underlying value orientations, objectives, roles, and indicators for success in these roles and associated policy analysis styles is provided by Mayer et al. (2004), as presented in Figure 1. 


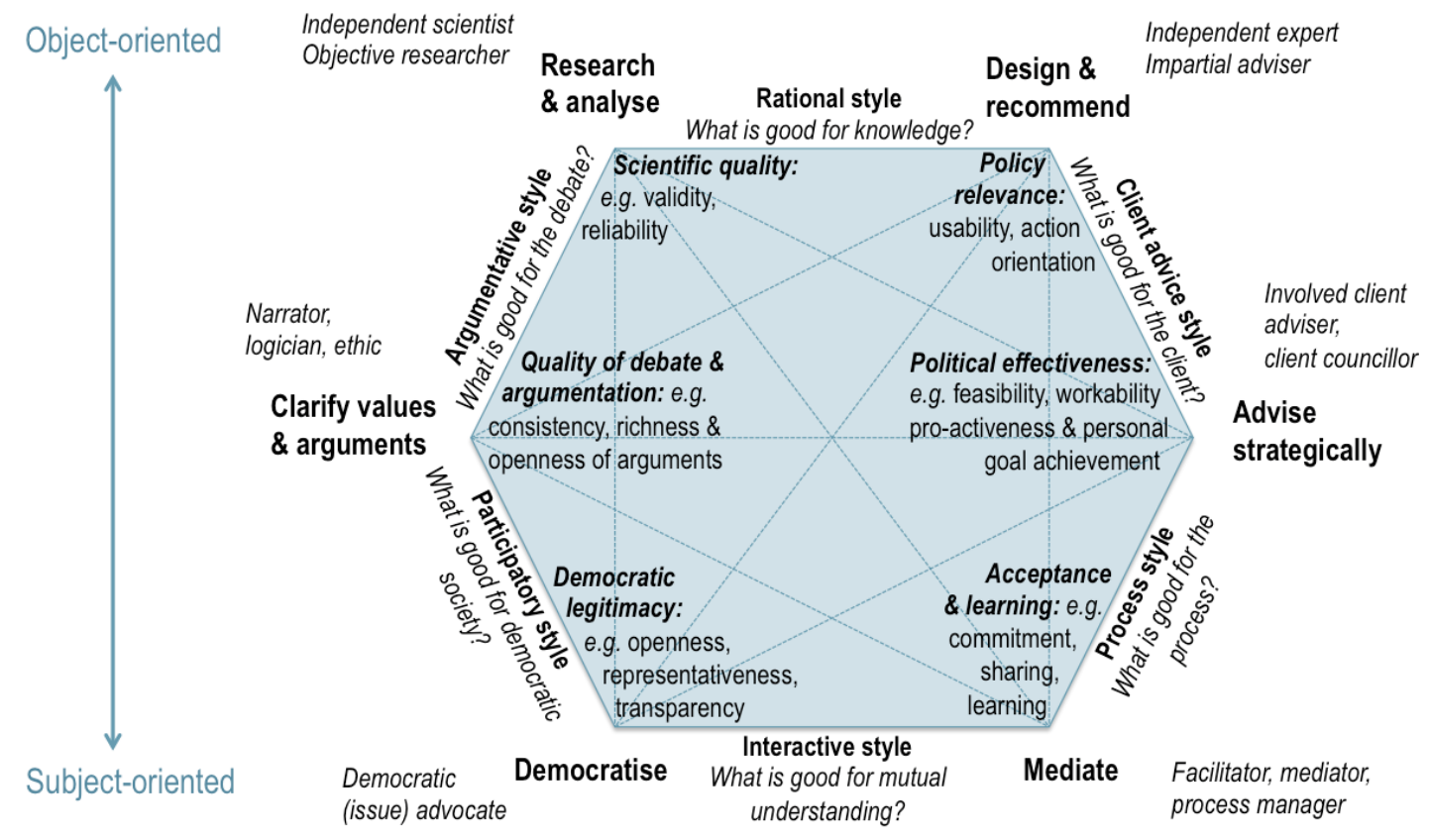

Values \&

Criteria

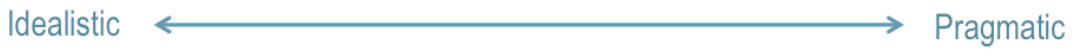

Figure 1: A conceptual model for understanding different types of policy analysis (adapted with permission from Mayer et al. 2004)

The policy analysis conceptual model in Figure 1 shows how values and roles vary based on dimensions such as: whether analysts are focused on 'facts' and objective analysis, or focused on people's views and the subjective creation of meaning and understanding; and whether they take a more idealistic or pragmatic approach to reality (and especially power and politics as it currently exists in the policy-making process). Actors involved in or driving these different types of policy analysis - represented at each corner of the hexagon in Figure 1 (i.e., researching and analysing policy-relevant data, designing and recommending policy-relevant options, advising strategically on what policy options might be politically effective, mediating conflicts between different values and policy options, democratizing the policy process or clarifying values and arguments of different actors in the policy process) - may not always be public servants or ministerial officials but can include academics, business consultants, international organizations or community members, especially when decision-making is opened up to stakeholder participation, as represented at the bottom of the hexagon in Figure 1.

These different forms of policy analysis have been fruitfully deployed by different actors across many application areas, including fire department positioning and dispatching, energy policy decision-making, air traffic control, national health planning, educational resource allocation or military manpower planning, to name but a few. Numerous examples are available in the literature, including those in Pollock et al. (1994) and Mayer et al. (2004). 
Different methods or 'analytics' can be used by policy analysts working in or across each of the six roles in Figure 1, which brings us to the need for discussing analytics in more depth; first related to business analytics where many innovative and valuable analytical methods have been developed and deployed, before we move on to the specificities of policy analytics.

\section{Analytics and Business Analytics}

We have already mentioned the public policy origins of Statistics and Operations Research, the traditional analytic disciplines par excellence. Over the last decade the growth in computational power and advances in big data technology have provided new perspectives in such disciplines, leading to that of 'Analytics' (Provost and Fawcett 2013), which are proving valuable in their ability to aid decision-makers in many business and industry areas.

Analytics can be divided into descriptive, predictive, and decisive types, and typically support the discovery and presentation of meaningful patterns in large data sets, in problems with rich recorded information, to quantify, describe, predict and improve performance of an organization. When referring to the business environment, we talk about business analytics (Chen et al. 2012; Albright and Winston 2014), which has been a prominent term in practitioner and academic discourse in recent years. Analytics often combines methods from statistics, operations research, machine learning and computer science, as well as disciplines like sociology, psychology and economics. Insights obtained from data are used to recommend action and guide decision-making and organizational planning. Output may be used as input for human decision-making or may feed a fully automated decision-making system. In contrast, the, by now, more traditional concept of business intelligence (Chen et al. 2012) tends to refer to querying, reporting, online analytical processing, and establishing alerts in connection with the application problem at hand.

In industry, an emphasis in the analytics domain has emerged around attempting to solve the challenges associated with analysing massive, complex data sets, often when such data is in a constant state of change, beyond the evolution and development of more conventional enterprise resource planning systems or data warehouses. Such data sets are commonly referred to as Big Data (O'Reilly 2012) and are characterized by three features typical of businesses that operate online transactional systems:

- Very large volumes of data generated. As a couple of examples, Walmart collects more than 2,5 petabytes per hour of customer transactions; Facebook collects 300 million pictures and 2.7 billion likes per day. Approximately 2.5 exabytes per day were being stored in 2012: a quantity which is supposedly doubling every 40 months.

- Very large heterogeneity of data generated, which may come from sources such as messages in blogs, images in social networks, emails, PDF files, geospatial data, sensor readings in a city, or GPS signals from mobile phones. Indeed, each 
of us could nowadays be viewed as a walking data generator, through our smartphone interactions.

- Very rapidly generated data. In many cases, the speed of data generation tends to be even more important than the volume of data generated, in the sense that we need to make decisions in real time and, therefore, we must exploit in real time information from data obtained in real time as well. A typical example would be loading fuel on an airplane, taking into account the most recent holding information at destination.

We thus have an ever increasing amount of digitized information stemming from increasingly cheap devices and sensors. Consequently, we face a new era in which there is a huge amount of digital information available on virtually any topic of potential interest to a business or a government. However, all too frequently such information is highly unstructured and somewhat unmanageable, and sometimes not all that relevant.

The analysis of such unstructured (non-sampled) data types is a major challenge gaining attention in the industry sector, leading to new paradigms like Data Science (Provost and Fawcett 2013) and Data Engineering (Shive 2013). Unstructured data differs from structured data in that its format varies widely and cannot be stored in traditional relational databases without significant efforts involving complex data transformations. This requires the so-called No SQL databases which are more scalable, including examples like CouchDB, MongoDB, Neo4J and Riak. Handling such masses of data requires a framework to manage computations over large data quantities, like MapReduce and its implementation Hadoop (due to Google) (see White 2012), which facilitate distributed processing over smaller data sets. Finally, we also require data storage infrastructures over Hadoop that facilitate data summary, query and analysis like Hive (due to Facebook) (see Capriolo et al. 2012). Within these technological developments, we should mention Python as the major programming language for numerical purposes in this new environment, as well as $\mathrm{R}$ for inference and prediction.

Besides technological developments, there are also new classes of data analytic methods that allow the extraction of information from masses of data. These go beyond traditional techniques like regression models, time series models, $k$-nearest neighbour classifiers, to more recent ones like classification and regression trees, machine ensembles or support vector machines (see James et al. 2013). Frequently, these require novel implementations, as in the case of the $\mathrm{R}$ functions biglm and bigmemory for linear regression in place of $\mathrm{lm}$. Another example is Mahout (Giacomelli 2013), which supports classification and clustering over Hadoop. Social network analysis, originally stemming from sociology (Wasserman 1994), and other analytics from 'soft operations research' that deal with the structuring and elicitation of meaning from qualitative data such as people's beliefs, values and preferences (e.g., Rosenhead and Mingers 2001), like cognitive mapping, are also gaining prominence, especially due to the data now available on these aspects from social networking websites and business stakeholder directories. 
In any case, data now seems to be more accessible to business professionals and managers than ever before. Thus, there is a huge opportunity to make better decisions using such data to increase revenue, and reduce cost and loss by building better products, detecting and preventing fraud, or improving customer engagement through personalized marketing and computational advertising. These are the objectives of what have been termed data-driven companies (see Lloyd 2011), which heavily promote evidence based decision-making (see De Marchi et al. 2015), with prime examples including Google, Facebook, Amazon, Walmart and the most advanced airlines.

\section{Policy Analytics}

We have described how the growth of data has led to new technological and scientific developments in what is now termed 'analytics', which when applied to providing business insights is called business analytics. Indeed, this term is becoming so popular that there are several universities providing degrees in that area. Yet, the same data issues are also being encountered in the public policy context. To name but a few, hospital admittances, electronic medical records, meteorological data, property sales, voter registration records, and data from surveillance cameras or cell phones are useful sources of large amounts of data for various government departments. Moreover, these data sources coexist with traditional sources of massive pre-designed data collection systems, including census, tax collection or governmental surveys.

Thus, we could think of applying the same approach of using analytics to support public policy decision-making, leading naturally to the concept of 'policy analytics'. This is a new term coined in the scientific literature in papers by Tsoukiàs et al. (2013) and De Marchi et al. (2015). However, interestingly when performing a search on the term, two companies emerge with such a name (Policy Analytics, Public Policy Analytics) and we can see that companies like Oracle, Booz-Allen-Hamilton or IBM have already included the term within their portfolio of activities. Carnegie Mellon University has also a track in Policy Analytics within their Public Policy program. Yet, as mentioned in the introduction, few government decisions have already benefitted from the systematic use of masses of data and evidence and cutting-edge modelling. By simple comparison with business applications, it is not difficult to envisage its enormous potential in problems like examining distribution and patterns of health events, developing rational infrastructure plans, using behavioural knowledge to encourage energy efficiency, developing personalized government services, enhancing touristic visits, identifying neighbourhoods with inadequate social services, building smart grids and cities, and many more.

Indeed, all roles of policy analysts outlined in Figure 1 could be matched with specific policy analytics methods, as shown in Figure 2. 


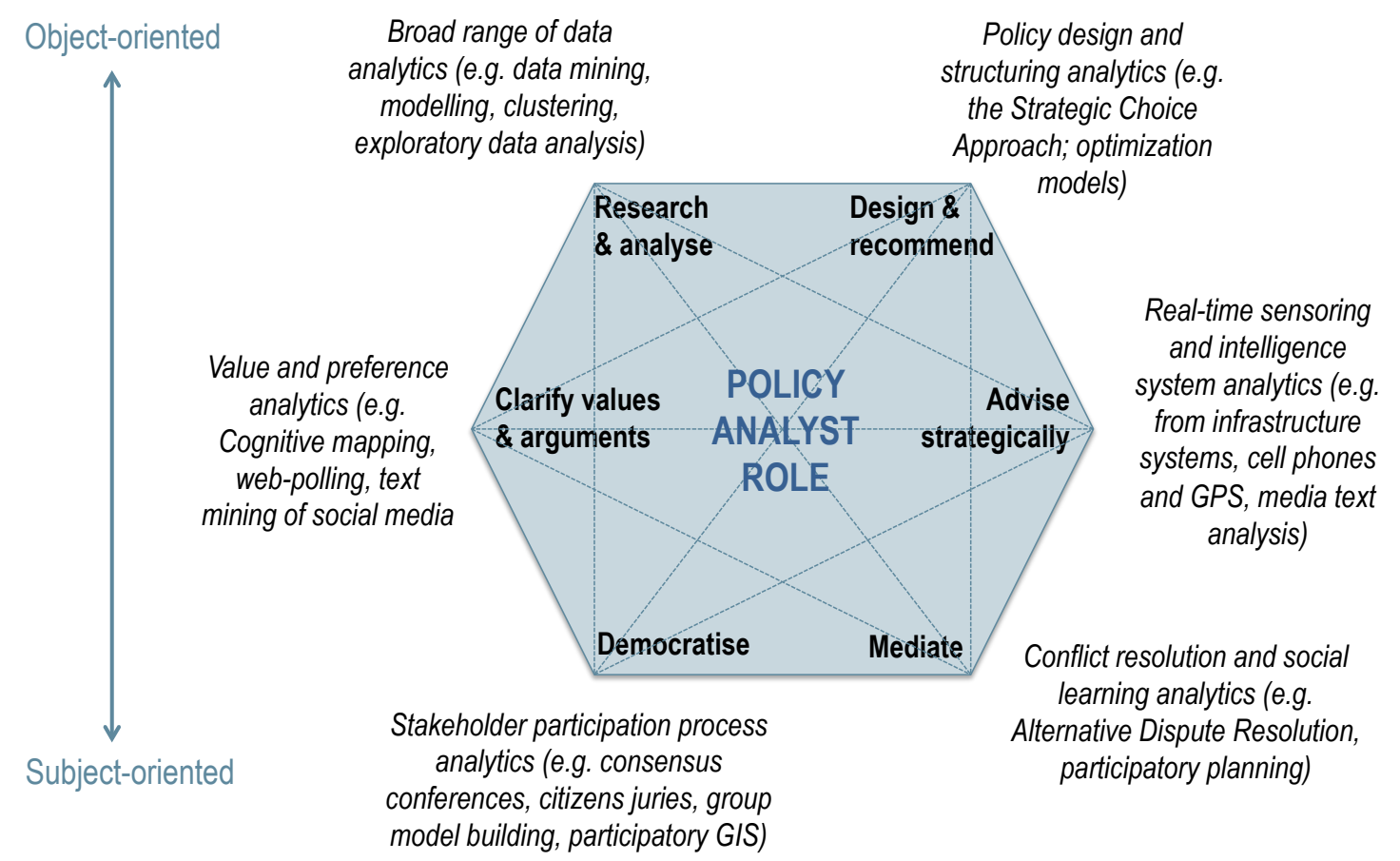

Values \&

Criteria

Figure 2: Example policy analytics linked to types of policy analysis

The analytics presented in Figure 2 are only general categories, and often a range of them will be used for policy analysis and policy-making support through the 'policy cycle' phases, such as cognitive mapping and text mining in the agenda-setting phase; group model building, multi-criteria analyses and simulation and optimization modelling in the analysis phase; participatory planning in the policy decision phase; resource allocation modelling and real-time operations optimization in the policy implementation phase; and, finally, a range of evaluation methods such as remote sensing, smart metering or participatory GIS/evaluation in the monitoring phase. They may also fit a range of policy making ideologies and processes, from past-looking evidence-based policy making (e.g., De Marchi et al. 2015) to future-looking intelligence-based policy making (e.g., Matthews 2014a,b) or more stakeholder-oriented democracy versions of the policy process (e.g., Dryzek 2000; Rios Insua and French 2010).

As cogently argued in the paper by De Marchi et al. (2015), and as we mentioned in our introduction, a key issue for comparing analytics when applied to business and policy is the substantial difference between their objectives, profit in the first case and a complex mixture of objectives in the second case, which need to be overseen by the preferences and values of policy makers, and, arguably, should take into account stakeholder preferences.

\section{Special Volume Contributions}


In order to obtain a relevant overview of the papers included in the volume, we have focused on three of their features:

- the policy application area;

- the main policy analytic techniques employed; and

- the policy phases involved in the study.

Submissions in this volume concern policy making or delivery in the areas of energy planning, urban transportation planning, medical emergency planning, healthcare, social services, national security, defence, government finance allocation, understanding public opinion, and fire and police services.

The special issue presents papers concerning both conceptual advances and innovative applications, recognizing that public sector innovation must balance the need for robust and convincing analysis with legitimate public expectations about transparency and opportunities for participation. Some of the techniques covered include text mining, exploratory data analysis, game theoretic models, large-scale mathematical optimization, clustering, support vector machines, spreadsheet models, and argumentation theory.

Papers also cover various phases of the policy cycle: from agenda setting and analysis to policy decisions, implementation and monitoring.

From a conceptual point of view, De Marchi, Lucertini and Tsoukiàs (2015), in their "From Evidence Based Policy Making to Policy Analytics" paper, set up the context of policy analytics. By first reviewing the basic concept of evidence based decisionmaking, stemming from evidence based medicine, they argue that the successes of business analytics do not directly translate to public policy making, essentially because of the need for taking the values of stakeholders into account, thus highlighting the importance of focusing on policy analytics. Scharaschkin and McBride (2015) also provide a conceptual contribution from the vantage point of the UK's National Audit Office. They discuss the task of making the assessment of whether the implementation of a particular policy has been 'value for money', as the National Audit Office is required to do. They provide a formal analysis of the mathematical structure of such a concept and discuss different sorts of value-for-money conclusions which are typically drawn in the reports of government auditors, illustrating their points with examples drawn from financial regulation, healthcare management and (public sector) human resource development.

A key area where policy analytics may be strategic is urban, energy and environmental planning, through the Smart Cities concept (see Goldsmith and Crawford 2014). One relevant case in this volume is that in Kumar, Nguyen and Teo (2015), who first analyse large databases of farecard data from cycle sharing users to ascertain the need for improving such a service in Singapore, and then find the optimal capacity expansion of the service through mathematical optimization problems. In another case, Zhang, Hu, Wang and Chen (2015) provide a market equilibrium biofuel model at the state of Iowa, 
taking into account the needs of crop producers, biofuel producers and consumers. The model leads to a large scale complementarity model that, when fed with data from relevant large databases, provides equilibrium production as well as prices for biofuels. MacKenzie, Baroud and Barker (2015) also make a contribution in this area, showing how optimization models can support resource allocation for environmental remediation after a disaster. They provide a relatively simple static model and a more complex dynamic model and illustrate these by applying them to the clean-up after the Deepwater Horizon oil spill.

Healthcare and medical services are also important areas for policy analytics, with several papers in this volume. The first one is by Aringhieri, Carello and Morale (2015) who study the problem of organizing emergency medical services in Milan. They develop a simulation model for ambulance dispatch and a more strategic model to calculate the size of the ambulance fleet needed to serve given demand and discuss how these problems can be designed. Brennan, Meier, Purshouse, Rafia, Meng and HillMacmanus (2015) deal with an important public health question, namely the effects of excessive alcohol consumption and the evaluation of policies to mitigate these. They discuss structuring and statistical fitting of a model of alcohol related behaviour and the valuation of the outcomes, with a particular focus on the process and role of modelling in a complex policy environment. Xiang and Zhuang (2015) focus on the problem of allocating resources after humanitarian disasters. They develop a queueing model in which customers may degenerate and die as they wait for service. They explore how this model can be used to allocate resources so as to optimize, for example, the expected death rate and explore how this model can be approximated in the event that it cannot be solved exactly.

ICT developments and large scale algorithmics are key for the development of policy analytics. One example is the paper by Alfaro, Cano-Montero, Gómez, Moguerza and Ortega (2015) who focus on how to combine supervised machine learning algorithms and unsupervised learning techniques for sentiment analysis and opinion mining purposes. They test their tools on real textual data available from comments introduced in a weblog connected to organizational and administrative affairs in a public educational institution and discuss how they could also be used to detect opinion trends related to policy decision-making or electoral campaigns.

The volume also explores the complexities and criteria for the effective functioning of more commonly used policy analytics, such as in the Hewson, Halliday, Gibson and Asthana (2015) work on financial spreadsheet models. They demonstrate the challenges of maintaining spreadsheet model transparency and improving technical quality assurance through applications to the UK Fire and Rescue, and Police service, financial allocation formulae, including the equity issues that can inadvertently (or purposefully) arise through the use of such models. Abi-Zeid and Tremblay (2015) observe that discussions about public policy issues can often be naturally structured through argumentation modelling frameworks. They analyse qualitative data arising from public 
hearings relating to a proposed hydroelectric project in Québec, in order to more deeply understand the grounds and justification for the responsible commission's decision.

Finally, in two papers, Xu, Zhuang and Liu (2015) and Xu and Zhuang (2015) study aspects of defence and homeland security, through defend-attack game theoretic models. In the first one, the authors integrate defend-attack games with supply chain risk management to study logistic support to an army. In the second, they study issues relating to learning and deception between a Defender and an Attacker.

\section{Future Perspectives}

Based on the sample provided by the papers in this volume, we believe that policy analytics is an emerging and vibrant area, which will lead to innovative ways of analysing and designing policies, and in turn enhancing public policy. Tsoukiàs et al. (2013) outline a research agenda for the field, suggesting a number of relevant research topics. We end here with a discussion of additional issues that might help in supporting this new field of research and public policy practice.

As we have mentioned, a key difference between analytics for business and for policy making relies on the need to take preferences over multiple consequences into account. One possible topic of interest would be to provide analytic methods for preferences, based on political surveys and consumer choices. At a deeper level, analytics may also be able to be used for understanding public policy related cultures and value-systems across and between countries in order to develop (or transfer between) more appropriate and acceptable policies in a broad range of governance systems.

A very important recent trend in public policy refers to participation methods and the involvement of citizens in public policy decision-making, beyond just voting in elections. The level of public participation at each stage of the policy making cycle, as defined earlier in Section 2, defines different democratic models which could be supported by a range of analytics, as exemplified in Figure 2. In the representative democratic model, the citizens choose representatives within a fixed period of time; those whose electoral promises better match their interests, who govern the society on behalf of the citizens and in accordance with what they understand is the public interest. Elected representatives take part in Stages 1 and 3, whereas civil servants and external expert advisers take part in Stages 2 and 4. Public participation is reduced to elections and opinion polls, mainly at the fifth monitoring stage, to find out about public satisfaction with current policies. Occasionally, the public may be consulted via referendum at Stage 3. The direct democratic model proposes that the public should be directly consulted at the policy decision stage in almost every policy decision, and possibly in Stages 1 and 2. Finally, the participatory democratic model proposes engaging the public at every stage in a variety of ways. It emphasizes public participation in Stages 1 and 2 of the policy making cycle, leading to final policy decision made in Stage 3 by the public and/or elected representatives. Especially when implemented through ICT, so-called e-participation, this may become another source of big data that may be incorporated into policy analytics. 
It is possible, however, that analytics have been somehow oversold. For example, when referring to Big Data, we can read expressions like "The data deluge makes the scientific method obsolete" (WIRED 2008) or "Big Data will save politics" (MIT Technology Review 2013), as if we just need to collect masses of data and, through automated solutions, obtain some kind of automated solution to any problem we might envisage. Although data is important, we also recognize that there is still a clear need to include expert judgment, or even lower-tech analytics in decision-making processes that could be used for policy 'crash-testing' or simulation to save money before costly policies with known risks of implementation failure are enacted. Future research may investigate the importance of interpretation, interpellation, intuition, ground-truthing in policy analytic work and translation of analytic outputs into action, thus determining relevant roles for machines, their masters and impacted parties in different processes of policy making and governance systems.

Finally, we should mention the possibility of combining the recent class of adversarial risk analysis models (see Banks et al. 2015), focused on competitive decision-making, with analytics methods applied over internet and social network data to drive competitive intelligence in security and defence contexts.

\section{Acknowledgements}

The idea for this special volume was sparked by a workshop on Policy Analytics organized at LAMSADE-CNRS, Paris, in December 2011 as a joint initiative between LAMSADE and DIMACS, where discussions with Alexis Tsoukiàs, Valerie Belton and a number of our other colleagues, both during and after the workshop, have supported the development of our thinking around the topic. The work of Katherine Daniell was supported by the HC Coombs Policy Forum. The HC Coombs Policy Forum and the Australian National Institute for Public Policy (ANIPP) received Australian Government funding under the 'Enhancing Public Policy Initiative'. The work of David Ríos is supported by the AXA-ICMAT Chair in Adversarial Risk Analysis, the AESARAC Agreement on Operational Safety, and the MINECO project MTM2014-56949C3-1-R. Discussions with colleagues at the ESF-COST IS1304 action on Expert Judgment and the HC Coombs Policy Forum are gratefully acknowledged. We are also grateful to the reviewers of the papers contained in this special volume, who, while they must remain anonymous, have generously contributed their time and expertise, and without whom the special volume would not be possible.

\section{References}

Abi-Zeid, I., \& Tremblay, J. (2015). Value-based argumentation for policy decision analysis - Methodology and an exploratory case study of a hydroelectric project in Québec. Annals of Operations Research. doi: 10.1007/s10479-014-1774-4. 
Albright, S., \& Winston, W. (2014). Business Analytics: Data Analysis and Decision Making. Cengage Learning.

Alfaro, C., Cano-Montero, J., Gómez, J., Moguerza, J. M., \& Ortega, F. (2015). A multi-stage method for content classification and opinion mining on weblog comments. Annals of Operations Research. doi: 10.1007/s10479-013-1449-6.

Althaus, C., Bridgman, P., \& Davis, G. (2007). The Australian Policy Handbook. Fourth Edition. Crows Nest: Allen and Unwin.

Aringhieri, R., Carello, G., \& Morale, D. (2015). Supporting decision making to improve the performance of an Italian Emergency Medical Service. Annals of Operations Research. doi: 10.1007/s10479-013-1487-0.

Banks, D., Rios, J., \& Rios Insua, D. (2015). Adversarial Risk Analysis. Francis Taylor.

Barnard, C., \& Simon, H. (1947). Administrative behavior. A study of decision-making processes in administrative organization. Free Press.

Blackett, P. M. S., \& Blackett, B. (1962). Studies of war, nuclear and conventional. Westport, CT: Greenwood Press.

Brennan, A., Meier, P., Purhouse, R., Raifia, R., Meng, Y., \& Hill-McManus, D. (2015). Developing Policy Analytics for Public Health Strategy and Decisions - The Sheffield Alcohol Policy Model Framework. Annals of Operations Research. doi: 10.1007/s10479-013-1451-z.

Capriolo, E., Warmpler, D., \& Rutherglen, J. (2012). Programming Hive. O’Reilly.

Chen, H., Chiang, R. H. L., \& Storey, V. C. (2012). Business intelligence and analytics: from big data to big impact. MIS Quarterly, 36, 1165-1188.

Clemen, R., \& Reilly, T. (2014). Making Hard Decisions. Cengage Learning.

Cohen, M. D., March, J. G., \& Olsen, J. P. (1972). A garbage can model of organizational choice. Administrative Science Quarterly, 17, 1-25.

Daniell, K. A. (2014). The Role of National Culture in Shaping Public Policy: A Review of the Literature. HC Coombs Policy Forum Discussion Paper. Canberra: The Australian National University.

De Marchi, G., Lucertini, G., \& Tsoukiàs, A. (2015). From Evidence Based Policy Making to Policy Analytics. Annals of Operations Research. doi: 10.1007/s10479-0141578-6.

Dryzek, J. S. (2000). Deliberative Democracy and Beyond: Liberals, Critics, Contestations. Oxford: Oxford University Press. 
Dunn, W. (1994). Public policy analysis: an introduction. 2nd ed. Englewood Cliffs: Prentice-Hall.

Fischer, F., Miller, G. J., \& Sidney, M. S. (Eds) (2007). Handbook of Public Policy Analysis: Theory, Politics and Methods. Boca Raton: CRC Press.

French, S., Papamichail, N., \& Maule, J. (2009). Decision Behaviour, Analysis and Support. Cambridge University Press.

Forester, J. (1993). Critical Theory, Public Policy, and Planning Practice: Towards a Critical Pragmatism. Albany, NY: State University of New York.

Giacomelli, P. (2013). Apache Mahout Cookbook. Packt Publishing.

Gigerenzer, G., Swijtink, Z., Porter, T., Daston, L., Beatty, J., \& Krueger, L. (1989). The empire of chance: How probability changed science and everyday life. Cambridge, UK: Cambridge University Press.

Goldsmith, S., \& Crawford, S. (2014). The Responsive City: Engaging Communities through Data-Smart Governance. Wiley.

Hewson, P. J., Halliday, J., Gibson, A., \& Asthana, S. (2015). Policy Analytics Need More than a Spreadsheet: A case study in funding formulae. Annals of Operations Research. doi: 10.1007/s10479-013-1475-4.

James, G., Witten, D., Hastie, T., \& Tibshirani, R. (2013). An Introduction to Statistical Learning. Springer.

Jann, W., \& Wegrich, K. (2007). Theories of the Policy Cycle. In: F. Fischer, G. J. Miller, M. S. Sidney (Eds), Handbook of Public Policy Analysis: Theory, Politics and Methods. Boca Raton: CRC Press.

Kingdon, J. W. (1984). Agendas, Alternatives, and Public Policies. Boston: Little, Brown.

Kumar, A., Nguyen, V. A., \& Teo, K. M. (2015). Commuter Cycling Policy in Singapore: A Farecard Data Analytics Based Approach. Annals of Operations Research. doi 10.1007/s10479-014-1585-7.

Kunreuther, K., \& Heal, G. (2003). Interdependent security. Journal of Risk and Uncertainty, 26, 231-249.

Lasswell, H. D. (1936). Who gets what, when and how. New York: Whittlesey House.

Lasswell, H. D. (1956). The decision process: seven categories of functional analysis. Bureau of Governmental Research, College of Business and Public Administration, University of Maryland. 
Lindblom, C. E., \& Woodhouse, E. J. (1968). The policy-making process. Volume 4. Englewood Cliffs, NJ: Prentice-Hall.

Lloyd, C. J. (2011). Data Driven Business Decisions. Wiley.

MacKenzie, C. A., Baroud, H., \& Barker, K. (2015). Static and Dynamic Resource Allocation Models for Recovery of Interdependent Systems: Application to the Deepwater Horizon Oil Spill. Annals of Operations Research. doi: 10.1007/s10479014-1696-1.

Matthews, M. (2009). Fostering creativity and innovation in cooperative federalismthe uncertainty and risk dimensions. In: J. Wanna, (Ed.) Critical reflections on Australian Public Policy (pp. http://epress.anu.edu.au/anzsog/critical/pdf/ch06.pdf. Accessed 13 June 2014.

Matthews, M. (2014a). Innovation and the productivity challenge in the public sector, Talk given at the inaugural Policy Reflection Forum at the Department of Communications, $\quad$ Wednesday $\quad 5$ March 2014, http://marklmatthews.files.wordpress.com/2014/02/dept-coms-talk-05-03-14-textfinal.pdf. Accessed 13 June 2014.

Matthews, M. (2014b). Is it time to shift from evidence-based policymaking to intelligence-based policymaking? HC Coombs Policy Forum Poster Presentation. Canberra: The Australian National University.

Mayer, I. S., Van Daalen, C. E., \& Bots, P. W. G. (2004). Perspectives on policy analyses: a framework for understanding and design. International Journal of Technology, Policy and Management, 4(2), 169-191.

MIT Technology Review (2013) Big Data Will Save Politics, MIT Technology Review, 116(2) http://www.technologyreview.com/magazine/2013/01/. Accessed 13 January 2015.

O'Reilly (2012). Big data now: 2012 edition, current perspectives from O'Reilly Media. O’Reilly.

Pollock, S. M., \& Maltz, M. D. (1994). Operations Research in the Public Sector: An introduction and a brief history. In S.M. Pollock, M. H. Rothkopf, \& A. Barnett, (Eds), Operations Research and the Public Sector (pp. 1-22). North Holland.

Pollock, S. M., (1994). Operations Research and the Public Sector. North Holland.

Provost, F., \& Fawcett, T. (2013). Data Science for Business. O’Reilly Media.

Quade, E. (1975). Analysis for Public Decisions. Rand Co.

Rios Insua, D., \& French, S. (Eds) (2010). e-Democracy: A Group Decision and Negotiation Perspective. Advances in Group Decision and Negotiation Series, Vol. 5, Part 2. Dordrecht: Springer. 
Rosenhead, J., \& Mingers, J. (2001). Rational Analysis for a Problematic World Revisited: Problem Structuring Methods for Complexity, Uncertainty and Conflict. Revised edn. Chichester, UK: John Wiley and Sons, Ltd.

Sabatier, P. A., \& Jenkins-Smith, H. (1993). Policy change and learning: an advocacy coalition approach. Boulder, CO.: Westview Press.

Scharaschkin, A., \& McBride, T. (2015). Policy analytics and accountability mechanisms: judging the 'value for money' of policy implementation. Annals of Operations Research. doi: 10.1007/s10479-014-1723-2.

Shive, B. (2013). Data Engineering. Technics Publications.

Stigler, S. (1990). The History of Statistics: The Measurement of Uncertainty before 1900. Belknap Press.

Stokey, E., \& Zeckhauser, R. (1978). A Primer for Policy Analysis. Norton.

Tsoukiàs, A., Montibeller, G., Lucertini, G., \& Belton, V. (2013). Policy analytics: an agenda for research and practice. EURO Journal on Decision Processes, 1, 115-134.

Wasserman, S. (1994). Social Network Analysis. Cambridge University Press.

White, T. (2012). Hadoop: The Definitive Guide. O'Reilly Media.

WIRED (2008) The End of Theory: The Data Deluge Makes the Scientific Method Obsolete, Wired Magazine: 16.07, http://archive.wired.com/science/discoveries/magazine/16-07/pb_theory. Accessed 13 January 2015.

Wolf, C (1993). Markets or Governments: Choosing Between Imperfect Alternatives. MIT Press.

Xu. J., \& Zhuang, J. (2015). Modeling Costly Learning and Counter-learning in an Defender-attacker Game with Private Defender Information. Annals of Operations Research. doi: 10.1007/s10479-014-1722-3.

Xiang, Y., \& Zhuang, J. (2015). A Medical Resource Allocation Model for Serving Emergency Victims with Deteriorating Health Conditions. Annals of Operations Research doi: 10.1007/s10479-014-1716-1.

Xu, J., Zhuang, J., \& Liu, Z. (2015). Modeling and Mitigating the Effects of Supply Chain Disruption in an Attacker-defender Game. Annals of Operations Research. doi: 10.1007/s10479-015-1810-z.

Zhang, L., Hu, G., Wang, L., \& Chen, Y. (2015). A Bottom-up Biofuel Market Equilibrium Model for Policy Analysis. Annals of Operations Research. doi: 10.1007/s10479-013-1497-y. 